\title{
Efeitos bioquímicos da suplementação de carboidratos após uma competição simulada de Short Duathlon Terrestre
}

\author{
Renata Mamus \\ M. Gisele Santos
}

\author{
Universidade Federal do Paraná \\ Curitiba \\ Brasil
}

\section{RESUMO}

\begin{abstract}
A proposta do presente estudo foi investigar os efeitos bioquímicos da suplementação de carboidratos em uma competição simulada de short duathlon terrestre. A amostra foi constituída de quatorze duatletas, aos quais foram dados suplementos de uma bebida com carboidrato em uma solução a $6 \%$ de maltodextrina (g1), placebo (g2) e solução a $6 \%$ de glicose (g3), em três momentos distintos da competição simulada: 30 minutos antes da prova $(500 \mathrm{ml})$, a cada 15 minutos durante essa competição $(200 \mathrm{ml})$ e imediatamente após o término desta $(300 \mathrm{ml})$. Amostras de sangue foram coletadas em dois momentos - antes e imediatamente após o final da competição - para análise da glicemia, lactato, insulina e cortisol. Verificaram-se diferenças significativas, em relação aos níveis de glicemia entre g1 e g2, na fase pós-competição. Quando analisado o lactato, também se verificou uma diferença significativa em gl e g2 na fase durante a competição. Da mesma forma, foram observadas diferenças significativas nas concentrações de cortisol durante a competição (g1) e pós-competição (g2). A conclusão desse estudo, baseada nos dados obtidos das amostras sanguíneas, foi que a suplementação de maltodextrina fornece indicativos bioquímicos que favorecem sua utilização em competições como o short duathlon terrestre.
\end{abstract}

Palavras-chave: carboidratos, competição, glicose, lactato, insulina, cortisol.

\section{ABSTRACT}

Biochemical Effects of Carbohydrates Supplementation in a Simulated Short Land Duathlon Competition

This study aimed to investigate the biochemical effects of carbohydrates supplementation in a simulated short land duathlon competition. Sample size consisted of 14 athletes that ingested supplements of a $6 \%$ maltodextrin solution (G1), placebo (G2), and a 6\% glucose solution (G3), in three different moments of the simulated competition: $30 \mathrm{~min}$ before de competition $(500 \mathrm{ml})$, every $15 \mathrm{~min}$ during the competition $(200 \mathrm{ml})$, and immediately after the end of the competition $(300 \mathrm{ml})$. Blood sampling was obtained during two stages of the competition before and immediately after the end - to blood glucose, lactate, insulin and cortisol analyses. We found significant differences at glucose concentrations between $G 1$ and $G 2$ after competition. When lactate concentrations were analysed, it was also found a significant difference in G1 and G2 during the competition, as well, in the cortisol concentrations during the competition (G1) and after competition (G2). We conclude that the maltodextrin supplementation provides biochemical evidence that favors its ingestion in simulated short land duathlon competition.

Key Words: carbohydrates, competition, glucose, lactate, insulin, cortisol. 


\section{INTRODUÇÃO}

O uso de manipulações dietéticas e o consumo de nutrientes com propósitos de aumento da performance por parte dos atletas são uma prática milenar. Esse é um fato compreensível quando se considera o ambiente altamente competitivo em que vivem os atletas, juntamente com o grau de motivação para vencer (1).

A prática da suplementação, em nosso século, passou a receber o status de "cientificamente embasada”, o que pode ser facilmente percebido com a variedade e quantidade de estudos científicos (2). Essa prática é um fenômeno que cresce a cada dia (3), devido principalmente à preocupação dos atletas quanto à melhora da saúde e performance física, tornando a relação entre dieta alimentar e desempenho físico fator preponderante para o bom desempenho desses competidores.

Apesar das evidências de que o uso de suplementos nutricionais é cada vez maior, seja com o intuito de hipertrofia, eliminar excesso de gordura corporal ou aumentar a performance, muitas questões sobre o consumo adequado de suplementos ainda precisam ser discutidas. As recomendações de dietas alimentares para atletas, assim como a suplementação de nutrientes, sempre estiveram em discussão, tendo em vista as características específicas de cada atividade física (4).

Observa-se, há algum tempo, que muitos estudos têm investigado os fatores que podem influenciar a suplementação de carboidratos, como o tempo (5, 6), frequência (1), conteúdo do suplemento $(8,6$, 11) e tipos de suplemento $(1,9,10)$.

Porém, quando se discute acerca da realização de exercícios de longa duração, sabe-se que um dos substratos degradado e utilizado é o carboidrato, o qual é armazenado na forma de glicogênio (12), ou seja, a forma polimérica de armazenamento da glicose (13). A glicose, por sua vez, exerce um papel importante, pelo fato de servir como combustível primário (glicogênio) para a performance do músculo, principalmente durante exercícios intensos (14). Dessa forma, recomenda-se a ingestão de carboidratos para atletas que realizam competições com duração igual ou superior a 1 hora, devido à sua rápida metabolização (15) e por serem digeridos e absorvidos mais rapidamente que as proteínas ou lipídios (16). Como os carboidratos são considerados o principal combustível durante o exercício de alta intensidade, aqueles atletas que treinam intensamente ou competem em dias seguidos e não consomem carboidratos de forma adequada, apresentam diminuição diária do glicogênio muscular, o que acarreta uma diminuição da performance física (17).

Porém, tratando-se de atletas, ressaltam os autores acima, que esses padrões alimentares se modificam, considerando como uma recomendação ideal as dietas com alto teor de carboidratos complexos e baixo teor de gordura, evidenciando que a ingestão alimentar dos atletas possui necessidades nutricionais diferentes. Quando analisa-se esportes de longa duração como o duathlon, que exige uma demanda energética elevada devido à combinação de duas modalidades esportivas (ciclismo e corrida), verifica-se a escassez na literatura de pesquisas sobre suplementação de carboidratos que envolvam esse esporte como um todo.

Além disso, muitas dessas pesquisas relatam alguns resultados diferentes com protocolos similares, inviabilizando ainda mais a escolha certa do protocolo a ser utilizado durante a competição.

Dessa forma, atletas e treinadores envolvidos sentem dificuldade no momento da escolha do suplemento ideal, visto que a maioria dos estudos investigam as modalidades esportivas separadamente, o que torna inviável escolher o tipo de carboidrato, tempo de ingestão e frequência ideal para esse esporte, que, além de solicitar grupos musculares diferentes, também possui necessidades específicas, de acordo com a realização de cada modalidade que o compõe. Considerando essas evidências, julgamos necessário e importante o desenvolvimento de um estudo que envolva a suplementação de carboidratos no esporte duathlon, para que assim se possa facilitar (através dos resultados obtidos) o treinamento desses atletas, em função da escolha de um protocolo ideal de ingestão de soluções à base de carboidratos.

Analisar os efeitos bioquímicos da suplementação de carboidratos, após uma competição simulada de short duathlon terrestre foi, assim, o objetivo deste estudo.

\section{METODOLOGIA}

Atletas de centros de treinamento das modalidades esportivas de duathlon foram convidados a participar do estudo, através de uma notificação oficial (documento escrito), na qual receberam todas as informações necessárias. 
Todos os atletas que concordaram em participar do estudo foram informados sobre a proposta da investigação, e assinaram um termo de consentimento que foi aprovado pelo Comitê de Ética da UFPR. A presente investigação enquadra-se no que se designa como um experimento duplo-cego.

Os atletas realizaram as duas modalidades esportivas que compõem o short duathlon terrestre - corrida (5 $\mathrm{Km})$, ciclismo $(20 \mathrm{Km})$ e corrida $(2,5 \mathrm{Km})$ - durante uma competição simulada e receberam suplementos líquidos com carboidratos e com placebo, antes, durante e após a competição. Amostras de sangue foram coletadas antes e após a competição, para análise dos níveis de glicemia, lactato, insulina e cortisol. A competição teve uma duração média de $1 \mathrm{~h} 15 \mathrm{~min}$.

\section{Amostra}

A seleção da amostra foi feita em regime de voluntariado, tendo a constituição dos grupos sido estabelecida de acordo com o $\mathrm{VO}_{2}$ máximo de cada atleta.

Participaram do estudo um total de 14 duatletas do sexo masculino, na faixa etária de 17 a 35 anos, participantes de centros de treinamento de Curitiba/Pr.

\section{Instrumentos e procedimentos}

Teste de consumo máximo de $\mathrm{O}_{2}$ : para realizar a distribuição dos atletas dentro dos diferentes grupos, foi realizado, na semana da competição simulada, o teste de consumo máximo de oxigênio direto através do protocolo de Bruce para esteira, uma vez que a amostra foi constituída de sujeitos regularmente ativos, com predominância de participação em modalidades de corrida.

O protocolo de Bruce tem a duração de 8 a 18 minutos, de acordo com o condicionamento físico de cada sujeito. Cada estágio dura 3 minutos, no qual a velocidade e inclinação da esteira mudam ao mesmo tempo (18).

A esteira utilizada para o teste foi da marca ECAFIX (EG700X).

O teste de consumo máximo foi realizado em circuito aberto, tendo a análise dos gases sido feita de forma direta, utilizando-se o analisador de gases da marca PARVO MEDICS (MMS 2400) e o software PARVO MEDICS TRUE MAX 2400.

Suplementação: os atletas foram divididos em três grupos: Grupo 1 (G1), Grupo 2 (G2) e Grupo 3 (G3). Os respectivos grupos receberam suplementa- ção de maltodextrina (G1) da marca D. N. A. (design nutrição avançada); placebo (G2) elaborado através de Suco Clight sabor abacaxi; e D-glicose Anidra (G3) da Labsynth Produtos. Foram adicionados $0,25 \mathrm{~g} / 1$ de suco clight sabor abacaxi nos suplementos de maltodextrina e glicose para dar sabor aos mesmos.

Os respectivos suplementos foram ingeridos em três momentos distintos da competição simulada.

No primeiro momento, a suplementação foi ingerida 30 minutos antes da competição, numa concentração a $6 \%$ de carboidratos $(30 \mathrm{~g} / \mathrm{CHO} / 500 \mathrm{ml})$.

No segundo momento, a suplementação foi ingerida a cada 15 minutos durante a competição, numa concentração a $6 \%$ de carboidratos $(12 \mathrm{~g} / \mathrm{CHO} / 200 \mathrm{ml})$. No terceiro momento, a suplementação foi ingerida imediatamente após a competição, numa concentração a $6 \%(18 \mathrm{~g} / \mathrm{CHO} / 300 \mathrm{ml})$.

Exames laboratoriais: Todas as análises bioquímicas foram realizadas no Serviço de Análises Clínicas do Hospital de Clínicas da Universidade Federal do Paraná (SAC/UFPR). As amostras de sangue foram obtidas através de coleta a vácuo, na veia antecubital de cada duatleta, em dois momentos da competição simulada, que ocorreram antes e imediatamente após o término da prova, após a ingestão do suplemento ( $\pm 2 \mathrm{~h} \mathrm{11)}$.

Cada amostra de sangue foi separada em dois tubos: um contendo fluoreto $(4 \mathrm{ml})$, para análise de glicose e lactato; e outro $(8 \mathrm{ml})$ contendo gel separador para análise de insulina e cortisol.

Os procedimentos operacionais para análise bioquímica de cada uma das amostras citadas foram, os seguintes:

Determinação da glicemia: A concentração de glicose circulante foi realizada pelo método Glicose Hexoquinase II (GLU H II) através do Kit Glicose Hexoquinase II e reativos ADVIA 1650 (Bayer). Determinação do lactato sérico: Determinado por método enzimático colorimétrico, segundo Engle \& Jones (19). Determinação da insulina sérica e cortisol: A insulina foi determinada pelo método Imunoensaio Imunométrico.

A análise da insulina foi realizada em equipamento de automação IMMULITE 2000, onde os reagentes necessários para a reação de quimiluminiscência já ficam acondicionados sob refrigeração no interior do equipamento, permanentemente. 


\section{Tratamento dos dados}

O programa STATISTICA for Windows (1999), versão 5.5 , foi utilizado para análise dos dados. As variáveis foram analisadas através do teste não-paramétrico Friedman, o qual buscou identificar se houve diferenças significativas entre as diferentes fases de um mesmo grupo. O teste Kruskal-Wallis também foi utilizado, com a finalidade de identificar se houve diferenças significativas entre os diferentes grupos. Com a finalidade de complementar a análise dos testes de Friedman e Kruskal-Walis, foi utilizado um teste de comparações múltiplas, para identificar onde ocorreram tais diferenças sifgnificativas. Para efeitos estatísticos, o nível de significância foi estabelecido em $\mathrm{p}<0,05$.

\section{RESULTADOS}

A tabela 1 apresenta os valores descritivos das características físicas dos duatletas que participaram do estudo.

Tabela 1: Valores médios e desvios-padrão do $\mathrm{VO}_{2}$ máx $\left(\mathrm{ml} \cdot \mathrm{Kg}^{-1} \cdot \mathrm{min}^{-1}\right]$.

\begin{tabular}{cc} 
Atletas $(n=14)$ & $V_{2}$ máx. \\
\hline$G 1$ & $62,14 \pm 7,83$ \\
$G 2$ & $62,14 \pm 6,86$ \\
$G 3$ & $64,41 \pm 4,36$
\end{tabular}

Na tabela 2, observa-se a descrição dos valores obtidos dos exames laboratoriais realizados em G1, G2 e G3 em cada fase da competição.

Tabela 2: Valores médios e desvios-padrão dos exames laboratoriais realizados em cada fase da competição.

\begin{tabular}{l|c|c|c|c}
\hline & GLICEMIA & INSULINA & LACTATO & CORTISOL \\
\hline ANTES & & & & \\
G1 & $5,4 \pm 0,3$ & $9,8 \pm 5,9$ & $1,4 \pm 0,2$ & $13,1 \pm 2,8$ \\
G2 & $5,2 \pm 0,4$ & $11,3 \pm 10,1$ & $2,0 \pm 1,1$ & $13,1 \pm 3,8$ \\
G3 & $5,3 \pm 0,9$ & $10,9 \pm 5,6$ & $2,0 \pm 1,6$ & $15,2 \pm 3,6$ \\
\hline APóS & & & & \\
G1 & $7,0 \pm 0,4^{*}+$ & $8,1 \pm 2,1$ & $5,2 \pm 1,2^{*}$ & $20,8 \pm 5,2^{*}$ \\
G2 & $4,7 \pm 0,7^{*}+$ & $6,8 \pm 4,6$ & $6,1 \pm 2,8^{*}$ & $25,1 \pm 4,3^{*}$ \\
G3 & - & - & - & - \\
\hline
\end{tabular}

G1 = grupo maltodextrina; $G 2$ = grupo placebo; $G 3$ = grupo glicose. Unidades de Medida: Glicemia, mmol/l; Insulina, $\mu \mathrm{Ul} / \mathrm{ml}$; Lactato, mmol/l; Cortisol, $\mu \mathrm{g} / \mathrm{DI}$. * Diferença significativa entre as fases do mesmo grupo; $p<0,05$; † Diferença significativa entre grupos diferentes; $p<0,05$. Não foi possível analisar a fase pós-competição do G3, devido à ocorrência de amostras hemolisadas e mortalidade experimental.
De acordo com a tabela 2, verifica-se que o G1 apresentou uma diferença significativa $(p=0,00674)$ nas concentrações de glicemia entre a fase antes e póscompetição, indicando um aumento dos níveis de glicose sanguínea durante o decorrer da competição. O G2 apresentou uma diminuição significativa $(\mathrm{p}=0,04980)$ nos níveis de glicemia em relação à fase pós-competição. Quando comparou-se os grupos G1 e G2, quanto aos níveis de glicemia, encontrou-se uma diferença significativa $(p=0,0086)$ na fase pós-competição.

Embora se tenha verificado uma elevação dos níveis desse hormônio ao final da competição no G1 (X = $15,1 \mu \mathrm{UI} / \mathrm{ml}$ ), nenhuma diferença significativa foi observada.

Com relação às concentrações de lactato, pode-se observar, de acordo com a tabela 2, que, tanto para o G1 como para G2, foram encontradas diferenças significativas na fase pós-competição ( $\mathrm{G} 1, \mathrm{p}=0,00832$; $\mathrm{G} 2, \mathrm{p}=0,015)$. Porém, quando comparou-se os níveis do lactato entre os grupos (G1, G2 e G3), não foram encontradas diferenças significativas em nenhuma das fases da competição.

Observou-se uma diferença significativa $(p=0,04078)$ nas concentrações de cortisol no G1 na fase pós-competição, verificando-se uma diminuição nos níveis desse hormônio.

Em relação às concentrações de cortisol no G2, verificou-se uma diferença significativa $(p=0,015)$ na fase após a competição, demonstrando uma elevação nas concentrações desse hormônio ao final da competição. Quando analisados os três grupos (G1, G2 e G3), nenhuma diferença significativa foi observada nos níveis de cortisol.

\section{DISCUSSÃO DOS RESULTADOS}

\section{Concentrações da glicemia e insulina.}

Dados deste estudo indicam que, quando os duatletas ingeriram maltodextrina (G1), houve um aumento significativo nos níveis de glicemia no decorrer da competição, quando comparado com G2 (placebo). O G2 apresentou uma queda nos níveis de glicemia, demonstrando uma diferença significativa na fase pós-competição.

Essa diferença significativa nos níveis de glicemia, entre o G1 e G2 na competição, é usualmente observada em estudos $(20,21,22,23,24,25$ e 26). Esse 
resultado mais elevado nos níveis de glicemia no G1 após a competição, deve-se principalmente à combinação da ingestão de CHO (maltodextrina) antes e durante a competição, a qual exerce um efeito adicional sobre a performance física, quando comparado com uma situação em que o $\mathrm{CHO}$ é ingerido, somente, em uma única fase da competição (27). Um dos efeitos adicionais observados da ingestão de CHO (maltodextrina) nas fases da competição, referese à elevação dos níveis de glicemia, como observado no resultado obtido pelo G1. Essa elevação é imprescindível para a performance física, pois altas concentrações de glicose favorecem a síntese de glicogênio muscular, e uma diminuição nessas concentrações pode levar à fadiga durante a competição (28). Essa eficácia da ingestão de CHO para aumentar a síntese de glicogênio pode ser explicada de duas formas: primeiro, por uma maior disponibilidade do substrato, através do aumento da concentração de glicose sanguínea, como verificado no G1; e segundo, pelo aumento da concentração da insulina sistêmica, considerada como um potencial ativador da síntese de glicogênio, que também pode ser verificado em G1, embora nenhuma diferença significativa tenha sido encontrada.

Tem sido demonstrado que o aumento da glicose circulante, através da ingestão de $\mathrm{CHO}$ (maltodextrina), atenua injúrias como a hipoglicemia e produção da glicose hepática (29).

Verifica-se, também, que a suplementação de $\mathrm{CHO}$ (maltodextrina) produz um aumento nos estoques de glicogênio muscular, permitindo que a competição se prolongue ou que a performance seja melhorada, mediante o retardo do início da fadiga. Este atraso da fadiga deve-se, principalmente, à prevenção do declínio da concentração da glicose sanguínea, a qual facilita proporções elevadas da oxidação de CHO durante os estágios finais da competição (23). Com relação ao aumento da glicemia na fase póscompetição do G1, quando comparado com o G2, verifica-se que esse resultado corrobora os de outros estudos $(28,29,30)$, que demonstraram que os níveis da glicemia são mais elevados após a ingestão de um suplemento à base de maltodextrina, quando comparado com outros tipos de $\mathrm{CHO}$ e placebo. Esse resultado é demonstrado tanto imediatamente após a competição, como verificado nos dados obti- dos dessa investigação, como também aos 40, 60 e, até, 100 minutos do período de recuperação $(28,30$, $31)$. Em outro estudo realizado com maratonistas, os níveis de glicemia após a competição foram significativamente diferentes entre os grupos que ingeriram $\mathrm{CHO}$ (maltodextrina) e placebo, indicando um nível mais elevado dessa concentração no grupo suplementado com CHO (22). Da mesma forma, obtiveram os mesmos resultados imediatamente após a competição (24).

Principalmente na fase após a competição, a ingestão de $\mathrm{CHO}$ é essencial para a reposição dos estoques de glicogênio, visto que nesse período há uma maior permeabilidade da membrana muscular para a glicose, o que favorece a síntese do glicogênio (28).

Outro resultado observado, na presente investigação, em relação aos níveis glicêmicos foi que, quando comparou-se o G1 e G3, nenhuma diferença significativa foi encontrada nas fases antes e durante a competição. Resultados contrários são demonstrados em outros estudos $(32,33)$, os quais relataram que, quando diferentes grupos ingeriram soluções à base de maltodextrina e glicose antes e durante a competição, os níveis de glicemia apresentaram-se mais elevados no grupo que ingeriu glicose. De acordo com a tabela 2, verifica-se um nível glicêmico semelhante nas fases antes e durante a competição, entre os respectivos grupos.

Possivelmente, uma diferença significativa entre o G1 e o G3 poderia ter sido encontrada se a análise bioquímica da fase pós-competição no G3 tivesse sido realizada, o que não foi possível devido a ocorrência de amostras hemolisadas e mortalidade experimental.

Observa-se, em geral, que a ingestão de soluções à base de glicose, durante um evento competitivo, resulta numa elevação rápida dos níveis de glicemia, o que favorece um aumento na utilização de $\mathrm{CHO}$ como combustível energético. Consequentemente, desenvolve-se a hipoglicemia e aumenta a taxa de utilização de glicogênio, resultando numa aceleração do início da exaustão.

Outros estudos têm demonstrado que a ingestão à base de polímeros de glicose (maltodextrina) na competição, reduziu a taxa de fadiga nos últimos 30 minutos de competição, devido principalmente à manutenção dos níveis elevados de glicemia $(6,34)$. 
O que corrobora os níveis elevados da glicemia observados no G1, fornecendo indicativos que beneficiam a performance na competição.

Quando comparou-se as respostas da insulina entre os grupos (G1, G2, G3), nenhuma diferença significativa foi obtida.

Estudos relataram uma hiperinsulinemia significativa quando ingerido glicose, comparado com a ingestão de maltodextrina (35). Como pode ser observado na tabela 2 , os níveis de insulina mantiveram-se semelhantes entre o G1 e G3.

Porém, houve uma elevação nas concentrações de insulina no G1, revelando um aumento progressivo do início ao fim da competição $(X=9,8-12,0-15,1$ $\mu \mathrm{UI} / \mathrm{ml})$, e uma diminuição no $\mathrm{G} 2(\mathrm{X}=11,3-6,5$ $6,8 \mu \mathrm{UI} / \mathrm{ml})$, embora nenhuma diferença significativa tenha sido observada em ambos os grupos.

Da mesma forma, outros estudos também relataram que nenhuma diferença significativa foi observada na competição, quando comparados diferentes tratamentos com CHO (maltodextrina) e placebo $(21,29$, 36 ), o que corrobora os resultados encontrados no presente estudo.

A importância de se manter níveis mais elevados da insulina durante a competição, deve-se ao fato de que a insulina aumenta a captação da glicose sanguínea para o músculo e, principalmente no período pós-competição, essa captação da glicose pelo músculo fica mais sensível à insulina, o que facilita a ressíntese dos estoques de glicogênio muscular . Verifica-se que, em algumas situações, quando o $\mathrm{CHO}$ (maltodextrina e glicose) é ingerido durante as fases da competição, as concentrações de insulina plasmática são tipicamente mantidas aos níveis de repouso ou, em alguns casos, aumentadas (37). Em geral, as concentrações de insulina tendem a diminuir durante a competição, o que se relaciona com dois fatores: a) primeiramente, com as alterações induzidas pela competição na quantidade de transportadores da glicose na membrana, b) e, também, com o grande aumento do fluxo sanguíneo ao músculo durante a competição, uma vez que a liberação da glicose é produto do fluxo sanguíneo muscular e da concentração de glicose no sangue. Portanto, durante a competição, mais glicose e insulina são liberadas do que durante o repouso e, como os músculos utilizam a glicose numa maior velocidade, é criado um gradiente para a difusão facilitada (17). Porém, quando há ingestão de $\mathrm{CHO}$ (maltodextrina), consequentemente, haverá uma maior disponibilidade de glicose sanguínea e, dessa forma, as concentrações plasmáticas de insulina tendem a elevar, para aumentar a captação de glicose pelo músculo (38), o que pode ser observado no G1.

A prática de ingerir $\mathrm{CHO}$ (maltodextrina) antes e durante a competição, aumenta os níveis de insulina que podem ser mantidos durante todo o decorrer da competição (39).

De outro lado, observa-se uma diminuição nos resultados das concentrações de insulina do G2, o que leva a uma mobilização da glicose dos estoques hepáticos, uso de gordura como energia e gliconeogênese (39), indicando, dessa forma, a necessidade do corpo de manter a concentração ideal de glicose sanguínea, em virtude de uma possível hipoglicemia (16).

\section{Concentrações do lactato sérico}

Foram encontradas diferenças significativas nas concentrações de lactato no G1 e G2 na fase após a competição $(\mathrm{G} 1=5,2$; $\mathrm{G} 2=6,1)$. Para ambas as condições, os níveis de lactato aumentaram no decorrer da competição e diminuíram na fase pós-competição, demonstrando um nível mais baixo para G1. Observa-se, em outros estudos, diferenças significativas entre grupos que ingeriram maltodextrina e placebo, em que as concentrações de lactato foram mais elevadas durante a competição no grupo suplementado com maltodextrina. No presente estudo, pode-se observar um aumento da concentração de lactato durante a competição, embora nenhuma diferença significativa tenha sido encontrada quando comparado o grupo suplementado com maltodextrina com o grupo placebo $(40,41)$.

O lactato pode contabilizar até $50 \%$ da síntese do glicogênio hepático em atletas. Isto se deve, principalmente, ao fato de que o lactato é um produto da desintegração do $\mathrm{CHO}$ (glicose e glicogênio), dessa forma, pode ser transformado novamente em qualquer um desses compostos no fígado e nos músculos (16). Com relação ao aumento nos níveis de lactato sanguíneo durante a competição, observado no G1 e G2 do presente estudo, verifica-se que esse aumento corrobora os resultados de outros estudos realizados com suplementação de CHO (maltodextrina e glico- 
se) com soluções a $6 \%(2,28,36,43)$. Verifica-se que esse acúmulo de lactato no sangue depende do equilíbrio entre a produção de lactato pelo músculo em atividade e sua remoção pelo fígado ou por outros tecidos. Ou seja, à medida que a intensidade da competição aumenta, o lactato sanguíneo pode aumentar, em razão de uma aceleração da produção de lactato ou de uma redução da taxa de remoção pelo fígado ou por outros tecidos. Da mesma forma que, à medida que a intensidade da competição aumenta, o fluxo sanguíneo aos músculos não-ativos, aos rins, ao fígado e ao trato gastrointestinal diminui, reduzindo a taxa de remoção de lactato (17).

Outro resultado obtido neste estudo foi que, quando comparou-se os três grupos (G1, G2 e G3) nas fases pré e durante a competição, nenhuma diferença significativa foi encontrada.

\section{Concentrações do cortisol}

Verifica-se que, no presente estudo, as concentrações do cortisol apresentaram diferenças significativas no G1 e G2 na fase após a competição.

Embora se tenha verificado, no presente estudo, que os níveis de cortisol tiveram uma elevação durante a competição nos três grupos (G1, G2 e G3), observou-se que somente no G1 esses níveis apresentaram uma diminuição ao final da competição.

O cortisol é um hormônio glicoregulador que, normalmente, aumenta durante os últimos estágios da competição, quando os níveis de carboidrato endógeno diminuem significativamente (44).

No presente estudo, a competição foi realizada numa intensidade média de $79 \%$ do $\mathrm{VO}_{2}$ máx. Observa-se que a secreção de cortisol aumenta de acordo com a intensidade da competição, pois verifica-se que, durante uma competição intensa (acima de $60 \% \mathrm{VO}_{2}$ max.), a taxa de secreção desse hormônio pelo córtex adrenal demonstra ser superior à sua taxa de remoção (16).

As concentrações de cortisol aumentam significativamente durante a competição prolongada, demonstrando elevações dramáticas em estados de hipoglicemia (39).

No entanto, com a ingestão de $\mathrm{CHO}$ (maltodextrina e glicose) o aumento do cortisol pode ser atenuado, quando comparado com a ingestão de placebo (31, 43). Esse resultado corrobora a diminuição nos níveis de cortisol observada no G1, confirmando o fato de que a ingestão de maltodextrina ameniza o aumento dos níveis do hormônio cortisol após uma competição intensa, quando comparado com o grupo placebo. Esses níveis mais baixos do cortisol pós-competição e após a suplementação com maltodextrina, devemse aos níveis mais altos de glicose plasmática, como observado no G1.

Foi observada uma queda na concentração de cortisol após a competição de ciclismo e corrida, quando os atletas ingeriram soluções com maltodextrina (31) e verificaram que, após competição de ciclismo (85\% $\mathrm{VO}_{2}$ máx.) com ingestão de maltodextrina $(6 \%)$, as concentrações de cortisol foram significativamente mais baixas imediatamente pós-competição, quando comparado com grupo que ingeriu placebo. Quando comparou-se os grupos G1, G2 e G3, nenhuma diferença significativa foi observada entre as fases antes e durante a competição na presente investigação (29). A ausência de diferença significativa entre os grupos G1, G2 e G3 verificada nesse estudo, pode ser explicada pelo fato de que as diferenças significativas geralmente encontradas em relação ao hormônio cortisol, quando comparados grupos que ingeriram diferentes tipos de $\mathrm{CHO}$ ou placebo, são apresentadas na fase pós-competição, o que não foi possível analisar nesta investigação, devido a algumas amostras hemolisadas e mortalidade experimental durante a competição.

\section{CONCLUSÕES}

De acordo com os resultados obtidos nessa investigação, pode-se chegar às seguintes conclusões: A suplementação realizada com maltodextrina (G1) forneceu indicativos que podem beneficiar a performance durante a competição de short duathlon terrestre, baseados na elevação dos níveis glicêmicos e da insulina e na diminuição dos níveis de lactato e cortisol (H1). Estes efeitos bioquímicos durante a competição são importantes para a melhora do rendimento físico, uma vez que diminuem a depleção do glicogênio no músculo e fígado, aumentam a captação de glicose e oxidação no músculo e cérebro, evitando-se uma possível fadiga no decorrer da competição. O benefício da suplementação de maltodextrina pode ser explicado, principalmente, pela manutenção de níveis altos de glicemia, o que evita conseqüentes 
injúrias como a hipoglicemia. Além disso, uma maior disponibilidade do substrato (glicogênio) para a realização do trabalho muscular também é fornecida com essa ingestão, evitando-se, assim, a fadiga muscular e melhorando a performance de resistência.

Dessa forma, pode-se concluir que a ingestão de suplementos com solução a $6 \%$ de maltodextrina, durante as fases de competição do short duathlon terrestre, ocasiona alterações significativas nas concentrações plasmáticas de glicose, lactato e cortisol plasmático, considerados os principais efeitos bioquímicos que podem retardar a fadiga durante a competição.

Esses achados corroboram os resultados prévios obtidos em estudos realizados com ciclistas, maratonistas e triatletas, que confirmam os benefícios da suplementação de maltodextrina nas fases de competição, mediante indicativos bioquímicos, o que torna o presente estudo apto à aplicação na rotina de treinamento e competição de duatletas.

No entanto, sugere-se que outros estudos sejam realizados com a finalidade de investigar outros efeitos bioquímicos da suplementação de diferentes tipos de carboidratos no short duathlon terrestre.

\section{CORRESPONDÊNCIA}

\section{Maria Gisele dos Santos}

Rua Brigadeiro Franco, 1909, Apto 903

80420 - 200 Curitiba, PR

BRASIL

mariagisele@yahoo.com

\section{REFERÊNCIAS BIBLIOGRÁFICAS}

1. Burke L.M., Collier G.R., Hargreaves M. (1993) Muscle glycogen storage after prolonged exercise: effect of the glycemic index of carbohydrates feedings. J Appl Physiol 75: 1019-1023.

2. Grandjean A.C.(1997) Diets of elite athletes: has the discipline of sports nutrition made in impact? Int J Sport Nutr 127: 874S.

3. Bacurau R.F. (2001). Nutrição e Suplementação Esportiva. $2^{\mathrm{a}}$ ed., São Paulo: Phorte Editora.

4. Correia M.I.T.D.(1996). Nutrição, Esporte e Saúde. Belo Horizonte: Health.

5. Levenhagen D.K., Gresham J.D., Carlson M.G., Maron D.J. (1969) Post-exercise nutrient intake timing in humans is critical to recovery of leg glucose and protein homeostasis. Am J Physiol Endocrinol Metab 280: E982-E993.

6. Ivy J.L., Katz A.L., Cutler C.L., Sherman W.M., Coyle, E.F. (1988). Muscle glycogen synthesis after exercise: effect of time of carbohydrate ingestion. J Appl Physiol 64: 1480-1485.

7. Doyle J.A., Sherman W.M., Strauss R.L (1993). Effects of eccentric and concentric exercise on muscle glycogen replenishment. J Appl Physiol 74: 1848-1855.

8. Bloom P.C.S, Hostmark A.T., Vaage O., Kardel K.R., Maehlum S. (1987). Effect of different post-exercise sugar diets on the rate of muscle glycogen synthesis. Med Sci Sports Exerc 19: 491-496.

9. Piehl A.K., Soderlund K., Hultman E. (2000). Muscle glycogen resynthesis rate in humans after supplementation of drinks containing carbohydrates with low and high molecular masses. Eur J Appl Physiol 81: 346-35.

10. Van Loon L.J.C, Saris W.H.S, Kruijshoop M., Wagenmakers A.J.M (2000). Maximizing post-exercise muscle glycogen synthesis: carbohydrate supplementation and the application of amino acid and protein hydrolysate mixtures. Am J Clin Nutr 72: 106-111.

11. Ivy J.L. (1998). Glycogen resynthesis after exercise: effect of carbohydrate intake. Int J Sports Med 19, Suppl: 142-146.

12. Hultman E. (1999). Physiological role of muscle glycogen in man, with special reference to exercise. Circulation Research 20-21 (suppl. I): I99-I114.

13. Nelson D.L., Cox M.M. (2000). Lehninger Principles of Biochemistry. $3^{\text {a }}$ ed.. New York: Worth.

14. Wolinsky I., Hickson J.J.F. (1996). Nutrição no exercício e no esporte. $2^{\text {a }}$ ed.. São Paulo: Roca.

15. Jacobs K.A, Sherman W.M. (1999). The efficacy of carbohydrate supplementation and chronic high-carbohydrate diets for improving endurance performance. Int J Sport Nutr 9(1): 92-115.

16. Mcardle W.D., Katch F.I., Katch V.L. (2003). Fisiologia do Exercício - Energia, Nutrição e Desempenho Humano. 5 ed. Rio de Janeiro: Guanabara Koogan.

17. Wilmore J.H., Costill D.L. (2001). Fisiologia do Esporte e do Exercício. São Paulo: Manole.

18. American College of Sport Medicine (2000). ACSM's guidelines for exercise testing and prescription. 6. ed. Philadelphia: Lippincott Williams \& Wilkins.

20. Coyle E.F., Coogan A.R., Hemmert M.K., Ivy J.L. (1986) Muscle glycogen utilization during prolonged strenuous exercise when fed carbohydrate. J Appl Physiol 61: 165-172.

21. Febbraio M.A., Chiu A., Angus D.J., Arkinstall M.J., Hawley J.A. (2000). Effects of carbohydrate ingestion before and during exercise on glucose kinetics and performance. J Appl Physiol 89: 2220-2226. 
22. Nieman D.C.S.L., Nehlsen-Cannarella L., Fagoaga O.R., Henson D.A., Utter A., Davis J.M., Williams F., Butterworth D.E. (2003). Influence of mode and carbohydrate on the cytokine response to heavy exertion. Med Sci Sports Exerc 30: 671-678.

23) Andrews J.L, Sedlock D.A., Flynn M.G., Navalta J.W. (2003). Carbohydrate loading and supplementation in endurance-trained women runners. J Appl Physiol 95: 584590.

24. Anslie P.N., Campbell I.T., Frayn K.N., Humphreys S.M.(2003). Physiological, metabolic, and performance implications of a prolonged hill walk: influence of energy intake. J Appl Physiol 94: 1075-1083.

25. Borsheim E, Cree G., Tipton K.D., Elliott T.A., Aarsland A., Wolfe, R. (2003). Effect of carbohydrate intake on net muscle protein synthesis during recovery from resistance exercise. J Appl Physiol 96: 674-678.

26. Volek J. S. (2004). Influence of Nutrition on Responses to Resistance Training. Med Sci Sports Exerc 36 (4): 689-698.

27. Widrick J.J., Costill D.L., Fink W.J., Hickey M.S. (1993). Carbohydrate feedings and exercise performance: effect of initial muscle glycogen concentration. J Appl Physiol 74(6): 2998-3005.

28. Bowtell J.L., Gelly K., Jackman M.L., Patel A. (2000) Effect of different carbohydrate drinks on whole body carbohydrate storage after exhaustive exercise. J Appl Physiol 88: 1529-1536.

29. Angus D.J., Febbraio M.A., Lasini D., Hargreaves M. (2001). Effect of carbohydrate ingestion on glucose kinetics during exercise in the heat. J Appl Physiol 90: 601-605.

30. Koch A.J., Potteiger J.A., Chan M.A., Benedict S.H., Frey B. (2001) Minimal influence of CHO ingestion on the immune responses following acute resistance exercise. Int $J$ Sport Nutr 11(2).

31. Grenn K.J., Croaker S.J., Rowbottom D.G. (2003). Carbohydrate supplementation and exercise induced changes in T-lymphocyte function. J Appl Physiol 95: 1216-1223.

32. Anderson G.H., Catherine N.L.A., Woodend D.M., Wolever T.M.S. (2002). Inverse association between the effect of carbohydrate on blood glucose and subsequente short-term food intake in young men. Am J Clin Nutr 76(50): 1023-1030.

33. Coogan A.R., Coyle E.F. (1987). Reversal of fatigue during prolonged exercise by carbohydrate infusion or ingestion. $J$ Appl Physiol 63(6): 2388-2395.

34. MacLaren D.P.M., Close G.L. (2000). Effect of carbohydrate supplementation on simulated exercise of rugby league referees. Ergonomics 43(10): 1528-1537.

35. Costill D.L., Coyle E., Dalsky G., Evans W., Fink W.J., Hoopes, D. (1977). Effects of elevated plasma FFA and insulin on muscle glycogen usage during exercise. J Appl Physiol 43: 695.

36. Ivy J.L., Goforth H.W., Damon B.M. (2002). Early post-exercise muscle glycogen recovery is enhanced with a carbohydrate-protein supplement. J Appl Physiol 93: 1337-1344.

37. Davis J.M., Brown A.S. (2002). Carbohydrates, Hormones and Endurance Performance. Sports Science Exchange 14 (1): $1-4$.

38. Volek J.S. (2004). Influence of Nutrition on Responses to Resistance Training. Med Sci Sports Exerc 36 (4): 689-696.
39. Garret W.E., Kirkendall D.T. (2000). Exercise and Sport Science. Philadelphia: Lippincott Williams \& Wilkins.

40. Walker J.L., Heigenhauser G.J.F., Hultman E., Spriet L.L. (2000). Dietary carbohydrate, muscle glycogen content, and endurance performance in well-trained women. J Appl Physiol 88: 2151-2158.

41. Lancha Jr A.H. (2002). Nutrição e metabolismo aplicados à atividade motora. São Paulo: Atheneu.

42. Fairchild T.J., Fletcher S., Steele P., Goodman C. (2003). Rapid carbohydrate loading after a short bout of near maximal-intensity exercise. Med Sci Sports Exerc 34:980986.

43. Utter A.C., Kang J., Robertson R.J., Nieman D.C. (2004). Effect of carbohydrate ingestion on ratings of perceived exertion during a marathon. Med Sci Sports Exerc 34(11): 1779-1784.

44. Smilios I., Pilianidis T., Karamouzis M., Tokmakidis P. (2003). Hormonal responses after various resistance exercise protocols. Med Sci Sports Exerc 35(4): 644-654. 